attempting to demonstrate environmental causes of myopia.

To give further scientific support to genetic influences, data have been gathered on myopia in twins, comparing the concordance rates in $\mathrm{MZ}$ and $\mathrm{DZ}$ pairs. The new data deal with a sample of twins located in a school population, and the world literature has been surveyed for nearsighted twins described in sufficient detail to be properly classified as to zygosity and refractive condition. Among a total of $106 \mathrm{MZ}$ pairs identified by the index twin having a myopia of at least one diopter, 100 are concordant for the disorder. Of 41 pairs of DZ twins, 12 are concordant.

These data are interpreted as further evidence for a very significant contribution by genetic factors. Studies of the children of two myopes are planned for the future, as there is strong support for recessive transmission. The postulated myopia gene appears to have a primary effect on the brain, resulting in enhanced intelligence, the influence on the eye then being viewed as a secondary complication.

John L. Karlsson, Ph.D., M.D., ${ }_{3} 80$ Thompson Avenue, Napa, California $9455^{8}$, USA

\section{A FEW REMARKS ON AN OCULISTIC AND ORTHOPTIC SGREENING OF SIXTY MZ TWIN PAIRS}

\section{R. BARBATI-GROUZET}

The Gregor Mendel Institute of Medical Genetics and Twin Research, Rome, Italy

An oculistic and orthoptic screening has been carried out on a sample of 120 twins aged 6 to Io years ( $30 \mathrm{MZ}$ male and 30 $M Z$ female pairs). A few remarks could be made, concerning both twins as such and the heritability of the traits under examination.

The twins appear to differ from the general population of singletons of the same age on account of a lower frequency of ametropia and strabismus as well as of a high frequency of epicanthus.

Dr.ssa R. Barbati-Crouzet, Istituto Mendel, Piazza Galeno 5, ooI6I Roma, Italy 